\title{
Guide to the Maps
}

The maps in this atlas focus on different developments-political, ethnic, religious-that have had a greater or lesser influence on the region at different periods of its history. The focus of each map is clarified in its accompanying commentary.

Colored areas represent sovereign states, political control and administration, ethnic or linguistic categories, or religious affiliations. Shades or patterns of a single color designate internal distinctions within a category. Colored arrows indicate movements by a designated group, military or migratory, and are defined on the map or in the map key.

Solid lines enclosing a broken black line indicate the boundaries of empires: the Russian and the Soviet (red), and the Ottoman and Persian (later Turkey and Iran; violet). Approximate boundaries are designated by broken lines, which are identified in the map keys.

Dark violet lines are used to indicate boundaries of dependent political entities, satellite states, or territories. Light violet lines indicate provincial and district borders. Broken violet lines indicate boundaries that are changing, approximate, or contested within the period covered by the map. Broken violet lines may also indicate the boundaries of highlander communities, their confederations, and their polities; such cases are indicated in the map keys.

Blue lines represent rivers, lakes, and coastlines.

Colored lines not mentioned here are identified in their respective maps or keys.

Names in roman indicate states, polities, provinces, and other administrative or territorial units; those in italic are geographic areas, historical provinces, ethnic groups or ethnolinguistic categories, highlander communities and confederations of nomadic peoples, or tribes. Further distinctions are detailed in individual map keys. Where there is no clear difference between polity and ethnic community (or confederation of communities) the choice of roman or italic type was made on the basis of whether polity or ethnicity was the focus of the map. Place names in roman represent towns, fortresses, or fortified towns. Place names in italic indicate villages, including stanitsas (fortified Cossack villages). Variant names are given in parentheses or after a virgule; where these have political or other significance they are explained in the relevant map key.

Because Russian political divisions do not correspond precisely with English divisions, the Russian names of the various political and other administrative divisions are included in brackets following the English names. Brackets are also used to designate dual names, contested toponyms, outdated ethnic categories, and other distinctions; these are specified in the individual maps.

Squares and circles represent, respectively, towns and villages. Red squares indicate capital cities and provincial centers, yellow squares and circles indicate district centers unless otherwise identified in the map key. Squares with an " $\mathrm{X}$ " identify fortresses or fortified towns; circles with an " $\mathrm{X}$ " are stanitsas on a few early maps.

White triangles represent key mountain peaks, five of which appear in each map to provide a basic geographical reference. These are Mounts Elbrus, Kazbek, and Bazarduzi in the Greater Caucasus mountain range and Mounts Aragats and Ararat in the Lesser Caucasus.

Other symbols (colored squares, circles, triangles, diamonds) used in the maps are identified in the relevant map keys.

In the early maps, red dotted lines designate the Russian defensive and communication lines, with the thickness of the dotted line indicating the respective importance of the defensive line and red circles identifying important fortified points.

In later maps, red lines indicate railroads, which came to the region in the 1870s. Active railroads are represented with a solid red line, railroads under construction with a broken red line, and planned railroads with a dotted red line. Additional representations of railroads are explained in individual map keys. Green lines indicate highways; active roads are shown by a solid line, roads under construction by a broken line, and planned roads by a dotted line.

None of the boundaries, toponyms, ethnonyms, or other designations used in the atlas imply endorsement of any government office or international institution. 
This page intentionally left blank 